\title{
Serum Long-Noncoding RNA H19 and $\beta$-Catenin as Biomarkers for Early Diagnosis of Colorectal Cancer in Egyptian Patients: A Case Control Study
}

\author{
Ayat Abdelrahman Abdelrahman Elshazly ${ }^{10}$ Mohammed Nageeb Desouky ${ }^{1}$ Iman Hassan Diab ${ }^{1}$ \\ Abeer Mahmoud Ali Ibrahim² ${ }^{2}$ Fatma Ibrahim Dwedar ${ }^{1}$ \\ ${ }^{1}$ Department of Medical Biochemistry, Faculty of Medicine, \\ Alexandria University, Alexandria, Egypt \\ 2 Department of Internal Medicine, Faculty of Medicine, Alexandria \\ University, Alexandria, Egypt \\ Address for correspondence Ayat Abdelrahman Abdelrahman \\ Elshazly, Lecturer of Medical Biochemistry, Department of Medical \\ Biochemistry, Faculty of Medicine, Alexandria University, Alexandria, \\ Egypt (e-mail: ayat_elshazly@yahoo.com).
}

J Coloproctol 2022;42(3):251-258.

\begin{abstract}
Keywords

- LnCRNA

- H 19

- $\beta$-catenin

- CRC

- colonic polyp

Colorectal cancer (CRC) is the third most prevalent cancer and the second most common cause of cancer death; however, its early detection can improve the survival. Colonic polyps are considered one of the CRC's major risk factors. Throughout many biological processes and malignancies, the non-coding RNAs have essential functions. Certain long noncoding RNAs (IncRNAs), including H19, were supposed to be CRC possible biomarkers. Also, H19 has been reported to play a role in regulating the activity of $\beta$-catenin, a protein that regulates cell-to-cell adhesion, as well as gene transcription. The current work aimed to investigate the potential significance of LncRNA H19 relative serum expression level by quantitative polymerase chain reaction ( $q-P C R$ ) and $\beta$-catenin by enzyme-linked immunosorbent assay (ELISA) as noninvasive biomarkers to discriminate between colorectal cancer and colonic polyps. The statistical analysis of the studied factors revealed that the serum expression of $\mathrm{H} 19$ and $\beta$-catenin in cancer cases were substantially greater than colonic polyp cases and normal control.

Conclusion The relative expressions of $\mathrm{H} 19$ and beta-catenin in the serum can significantly discriminate patients with CRC from those with polyp and normal controls, which could help when screening for CRC.
\end{abstract}

\section{Introduction}

Worldwide, colorectal cancer (CRC) is the third most common type of cancer, and it accounts for $10 \%$ of all cancerrelated mortality. ${ }^{1}$ Early detection of colon cancer can improve survival. $^{2}$ Among the essential risk factors, tubular and villous adenomatous colonic polyps are determined as CRC precursor lesions. From those adenomas, 95\% of sporadic CRC originates. ${ }^{3}$

Over the years, CRC begins to grow from adenomas even with no symptoms. It is believed that small lesions take $\sim 10$ years to develop to be invasive cancer. This protracted received

April 21, 2021

accepted after revision

August 6, 2021

published online

February 11, 2022
DOI https://doi.org/

$10.1055 / \mathrm{s}-0042-1742668$.

ISSN 2237-9363.

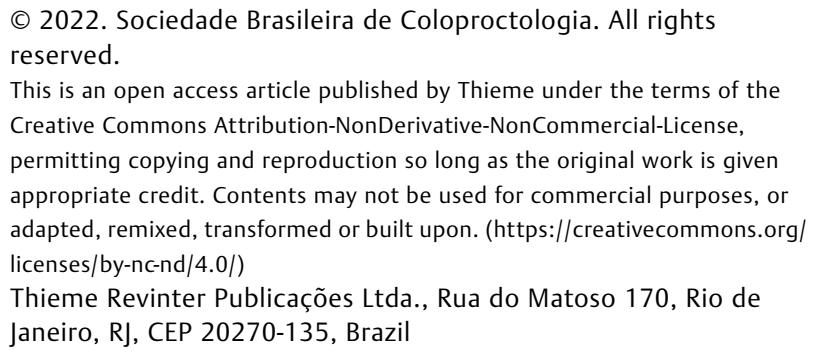

(C) 2022. Sociedade Brasileira de Coloproctologia. All rights reserved.

This is an open access article published by Thieme under the terms of the Creative Commons Attribution-NonDerivative-NonCommercial-License, permitting copying and reproduction so long as the original work is given appropriate credit. Contents may not be used for commercial purposes, or adapted, remixed, transformed or built upon. (https://creativecommons.org/ licenses/by-nc-nd/4.0/)

Thieme Revinter Publicações Ltda., Rua do Matoso 170, Rio de Janeiro, RJ, CEP 20270-135, Brazil 
duration from adenoma to carcinoma seems to be of great benefit for early detection and diagnosis of colon cancer and also for its prevention. ${ }^{2}$

Screening by colonoscopy and sigmoidoscopy results in a reduction of both incidence and mortality of CRC. ${ }^{4}$ Despite the benefit, they are invasive with high cost. ${ }^{5}$ Fecal immunochemical test (FIT), although noninvasive, shows low sensitivity, which limits its use in practice. ${ }^{6}$ Until now, it is still difficult to predict whether Cologuard (Exact Sciences Corporation, Madison, WI, USA), which is also a fecal test with a significantly higher cost, will have any better performance. ${ }^{7}$

Blood markers for CRC include carcinoembryonic antigen (CEA) and carbohydrate antigen CA 19-9. They are normally used to follow patients with known cancers, predict prognosis, assess response to treatment, and monitor for recurrence, but they are not sensitive enough for a diagnosis of CRC. ${ }^{8}$

A strategy for a higher screening rate and early diagnosis of CRC is urgently needed, and blood-based biomarkers are promising.

Non-coding ribonucleic acids (ncRNAs), which are RNA groups that do not code proteins, represent most of the transcripts of all RNAs inside the cell. It includes short $(\sim 22$ nucleotides) microRNAs (miRNAs) and long non-coding RNAs (lncRNAs) (of $>200$ nucleotides). At the epigenetic levels, lncRNAs control gene expressions. Moreover, lncRNAs play important roles in the proliferation, apoptosis, and invasiveness of tumor cells as well as in the metastatic capacity of cancers. ${ }^{9}$

Importantly, lncRNAs were also found in human serum, plasma, urine, and other body fluids, where they are remarkably stable. These findings raised the possibility that circulating lncRNAs can be considered as a potential biomarker for the diagnosis of diseases, including cancer. ${ }^{10}$

Certain IncRNAs, one of which is $\mathrm{H} 19$, were recognized as possible biomarkers for CRC. The $\mathrm{H} 19$ gene encodes the covered, segmented, and polyadenylated $2.7 \mathrm{~kb}$ RNA, rather than a protein. The H19 IncRNA enhances the invasive and migratory potential of cancer cells by regulating target genes. ${ }^{11}$ Also, $\mathrm{H} 19$ can regulate the activity of $\beta$-catenin, ${ }^{12}$ which is a protein encoded via the catenin $\beta 1$ (CTNNB1) gene. Beta-catenin is a target for miR-148b miR-200a. The H19 IncRNA can act as a competing endogenous RNA (ceRNA) of both miR-148b and miR-200a, leading to enhanced expression of $\beta$-catenin. ${ }^{13,14}$ Also, H19 decreases cyclin-dependent protein kinase 8 (CDK8) expression by interacting with macroH2A, which is one of the core histones proteins that act as a regulator of $C D K 8$. This reduction in CDK8 expression underlies changes in $\beta$-catenin activity by changing its phosphorylation. $^{15}$

Beta-catenin acts as a regulator and coordinator for the adhesion between cells and is involved in the regulation of gene expression. In addition, $\beta$-catenin is a subdivision of the complex E-cadherin protein and could be considered as an intracellular transducer of signal through the wingless integrated (Wnt) signaling pathway that has a significant role in the control of the proliferation of intestinal cells. ${ }^{16}$
The measurements of $\mathrm{H} 19$ were performed in the plasma of patients with gastric and breast cancer, and its role as a potential non-invasive biomarker was shown in the two tumors.

However, the H19 level in the plasma of CRC patients is still unclear. ${ }^{17}$ Also, many studies had focused on the detection of higher levels of $\beta$-catenin in cancer tissues but not in serum. ${ }^{18}$ The present work aimed to examine the potential significance of lncRNA H19 relative serum expression level in addition to $\beta$-catenin as noninvasive biomarkers to discriminate between CRC and colonic polyps.

\section{Materials and Methods}

To achieve the goal of the study, we enrolled 40 CRC (group I), 40 colorectal polyp patients diagnosed by colonoscopy (group II) who attended the department of gastroenterology of the Alexandria Main University Hospital, and 20 healthy controls (group III) of matched age and gender.

After a thorough clarification of all procedure steps, written informed consent was received from all participants. The ethics review board of the Faculty of Medicine at Alexandria University approved the study under the number 021023.

The exclusion criteria were patients with cardiac or hepatic disorders, renal diseases, autoimmune diseases, familial adenomatous polyposis (FAP), and malignancies other than CRC. Also, patients who had received systemic chemotherapy and radiotherapy, patients who were unwilling to participate, and patients who did not sign the informed consent form swere excluded from this work.

For the case-control study, the sampling size has been determined utilizing the epi info software, considering a power of $80 \%$ and a confidence level of $95 \%$.

All patients of groups I, II, and III were evaluated clinically by taking a full history and complete clinical examination; then, $10 \mathrm{ml}$ of venous blood was collected from them. Each blood sample was then divided into three aliquots: an ethylene diamine tetraacetic acid (EDTA) tube, a citrated tube, and a plain tube. In the latter, the blood was allowed to clot, then centrifuged at $1,200 \mathrm{xg}$ for 10 minutes to separate serum samples, which were kept frozen at $-80^{\circ} \mathrm{C}$ until use.

In groups I and II, the colon was evaluated by colonoscopy, and the obtained biopsy was referred for histopathological examination. Determination of $\mathrm{H} 19$ relative serum expression level using real-time quantitative polymerase chain reaction (q-PCR) and measurement of serum level of $\beta$ catenin using enzyme-linked immunosorbent assay (ELISA) were done for all groups

Total RNA separation from serum samples was performed using the Qiagen miRNeasy Mini Kit. (Cat. No. 217004). A nanodropper 2,000/2,000cc was used for measuring RNA condensation and purity; then, the High Capacity cDNA Reverse Transcription Kit was used for the synthesis of complementary deoxyribonucleic acids (cDNA) (Applied Biosystems, USA). ${ }^{19}$ Each reaction contained $10 \mu \mathrm{g}$ of RNA extract, $2 \mu$ l of reverse transcriptase buffer, $0.8 \mu$ of deoxynucleotide triphosphate (dNTP), $1 \mu$ of reverse transcriptase, 
$1 \mu l$ of RNase inhibitor, $2 \mu$ RT of random primers, and the total volume amounted to $20 \mu \mathrm{l}$, by adding nuclease-free water. The thermal cycle has been set for 10,120 , and 5minute hold at $25^{\circ} \mathrm{C}, 37^{\circ} \mathrm{C}$, and $85^{\circ} \mathrm{C}$, respectively. Finally, at $4^{\circ} \mathrm{C}$ for 24 hours if not directly stored at $-20^{\circ} \mathrm{C}$; then, the cycle was turned off. Quantitative PCR has been performed using the Applied Biosystems Step-one Real-time via Thermo Scientific Maxima SYBR Green qPCR Master Mix (2X) (Thermo Scientific, Cat. No. K0251) (Thermo Fisher Scientific, Waltham, MA, USA). Specific primers for H19 were as follows: forward primer 5-TGCTGCACTTTACAACCACTG-3, and a reverse primer 5-ATGGTGTCTTTGATGTTGGGC-3. Glyceraldehyde 3-phosphate dehydrogenase (GAPDH) was used as an endogenous control with a forward primer $5^{\prime}$-GAAGGTGAAGGTCGGAGTCAAC-3' and a reverse primer 5'-CAGAGTTAAAAGCAGCCCTGGT-3'. Each reaction consisted of $12.5 \mu \mathrm{l}$ of Maxima SYBR Green qPCR Master Mix (2X), $1 \mu$ l of forward primer ( $50 \mathrm{pmol}), 1 \mu \mathrm{l}$ of reverse primer ( $50 \mathrm{pmol}), 0.1 \mu \mathrm{l}$ of ROX Solution, $7.4 \mu$ l of nuclease-free water, and $3 \mu$ of cDNA. In duplications, specimens have been analyzed. No template control was used in every assay. Quantitative PCR has been set as the following: 10 minutes premier cycle at $95^{\circ} \mathrm{C}$, followed by 3-step cycling: (40 cycles) denaturation at $95^{\circ}$ $\mathrm{C}$, for 15 seconds; annealing at $56^{\circ} \mathrm{C}$ for $\mathrm{H} 19$ and $65^{\circ} \mathrm{C}$ for the GAPDH gene for 30 seconds, and the extension step at $72^{\circ} \mathrm{C}$ for 30 seconds. Melting curves were done to verify the specificity and identity of the product. A relative quantitative method ( $R Q=2-\Delta \Delta C T)$ has been used to calculate the fold modification between a sample and a normal control for H19.

\section{Determination of the serum level of human $\beta$-catenin} was performed by ELISA (NOVA, Beijing, China).

This type of ELISA kit used was the sandwich-ELISA. Betacatenin antibodies were used for precoating the microelisa strip plate. Afterward, wells have then been used for standards or specimens; then, a horseradish peroxidase (HRP)conjugated antibody specified for $\beta$-catenin was added to every well and incubated. Wells containing $\beta$-catenin and anti-HRP conjugated $\beta$-catenin turned blue, followed by yellow coloration after adding the stopping solution. Spectrophotometric measurement of the optical density (OD) was done at $450 \mathrm{~nm}$ wavelength.

\section{The Data Statistical Analysis ${ }^{20}$ :}

Using the IBM SPSS Statistics for Windows, Version 20.0 software package (IBM Corp., Armonk, NY, USA), the data have been analyzed and added to the computer. ${ }^{21}$

\section{Results}

Statistical comparisons of the subjects' age showed significant differences between groups I and II. In group I, the age range was from 40 to 79 years, with a mean value of $55.6 \pm 9.37$. While the mean age in group II was $50.48 \pm 7.29$ years for a range from 40 to 68 years. In group III, the age range was from 32 to 67 , with a mean value of $52.95 \pm 8.68$ years. Distribution of the studied cases in group I according to stage demonstrated in - Fig. 1.

The hemoglobin level in group I ranged from 7.5 to $13.9 \mathrm{~g} /$ $\mathrm{dl}$, in group II from 8.9 to $14.7 \mathrm{~g} / \mathrm{dl}$, while in group III it was

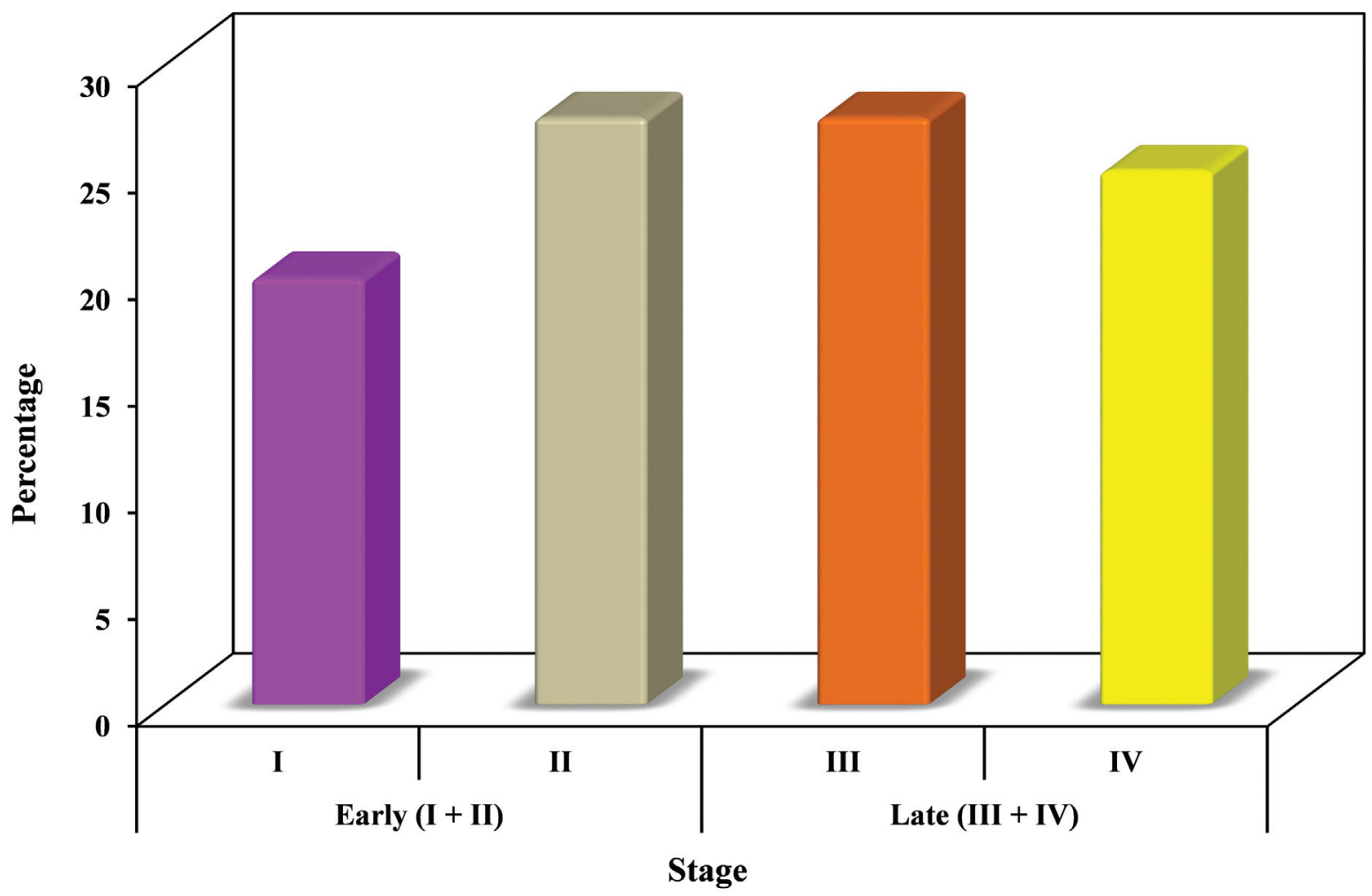

Fig. 1 Distribution of the studied cases according to colorectal cancer stage in group I. 
between 9.8 to $14.7 \mathrm{~g} / \mathrm{dl}$. In group I, the level of hemoglobin was significantly lower than that in groups II and III, but no significant difference has been found among groups II and III. The demographic and laboratory outcomes of all groups are demonstrated in - Table $\mathbf{1}$.

Both CEA and CA19-9 levels in group I were significantly higher than those in groups II and III; however, the difference between the levels in groups II and III was not significant. The CEA and CA 19-9 levels were demonstrated in - Table (1).

The level of H19 in group I was significantly higher than that in groups II and III, while no significant difference between groups II and III was found. The level of $\beta$-catenin in group I was significantly greater than that in groups II and III, while the levels in groups II and III had no significant difference as shown on - Table (2).

There was no significant correlation between relative serum expression levels of $\mathrm{H} 19$ and different cancer stages ( $r: 0.112$, p: 0.49), nor $\beta$-catenin and different cancer stages (r: 0.269, p: 0.09).

Receiver-operating characteristic (ROC) curve analysis of H19 relative serum expression, $\beta$-catenin, CEA serum level, and serum CA19,9 activity to predict group I from group II patients as in - Table 3, - Fig. 2 and group I from group III in -Table 4.

Table 1 Demographic data and laboratory results of the studied groups

\begin{tabular}{|c|c|c|c|c|c|c|}
\hline & \multicolumn{2}{|c|}{$\begin{array}{l}\text { Group } 1 \\
(n=40)\end{array}$} & \multicolumn{2}{|c|}{$\begin{array}{l}\text { Group } 2 \\
(n=40)\end{array}$} & \multicolumn{2}{|c|}{$\begin{array}{l}\text { Group } 3 \\
(n=20)\end{array}$} \\
\hline & No. & $\%$ & No. & $\%$ & No. & $\%$ \\
\hline \multicolumn{7}{|l|}{ Sex } \\
\hline Male & 17 & 42.5 & 21 & 52.5 & 5 & 25.0 \\
\hline Female & 23 & 57.5 & 19 & 47.5 & 15 & 75.0 \\
\hline \multicolumn{7}{|l|}{ Age (years) } \\
\hline Min.-Max. & \multicolumn{2}{|c|}{$40.0-79.0$} & \multicolumn{2}{|c|}{$40.0-68.0$} & \multicolumn{2}{|c|}{$32.0-67.0$} \\
\hline Mean \pm SD & \multicolumn{2}{|c|}{$55.60 \pm 9.37$} & \multicolumn{2}{|c|}{$50.48 \pm 7.29$} & \multicolumn{2}{|c|}{$52.95 \pm 8.68$} \\
\hline Significance & \multicolumn{6}{|c|}{$\mathrm{p}_{1}=0.021^{*}, \mathrm{p}_{2}=0.489, \mathrm{p}_{3}=0.535$} \\
\hline \multicolumn{7}{|l|}{ HB (g/dl) } \\
\hline Mean \pm SD & 10.1 & & 11.8 & & 12.4 & \\
\hline Significance & \multicolumn{6}{|c|}{$\mathrm{p}_{1}<0.001^{*}, \mathrm{p}_{2}<0.001^{*}, \mathrm{p}_{3}=0.278$} \\
\hline \multicolumn{7}{|c|}{$\begin{array}{l}\text { Erythrocytic sedimentation rate } \\
(\mathrm{ESR})(\mathrm{mm} / \mathrm{h})\end{array}$} \\
\hline Median & 67.5 & $96.50)$ & 29.5 & 42.50) & 14.5 & 21.0) \\
\hline Significance & \multicolumn{6}{|c|}{$\mathrm{p}_{1}=0.007^{*}, \mathrm{p}_{2}<0.001^{*}, \mathrm{p}_{3}=0.006^{*}$} \\
\hline \multicolumn{7}{|c|}{ Serum Albumin (g/dl) } \\
\hline Mean \pm SD & \multicolumn{2}{|c|}{$28.95 \pm 7.33$} & \multicolumn{2}{|c|}{$35.74 \pm 5.46$} & \multicolumn{2}{|c|}{$40.14 \pm 3.29$} \\
\hline Significance & \multicolumn{6}{|c|}{$\mathrm{p}_{1}<0.001^{*}, \mathrm{p}_{2}<0.001^{*}, \mathrm{p}_{3}=0.023^{*}$} \\
\hline \multicolumn{7}{|c|}{ C- reactive protein (CRP) (mg/l) } \\
\hline Median & \multicolumn{2}{|c|}{$7.30(4.0-9.10)$} & \multicolumn{2}{|c|}{$3.05(2.0-4.30)$} & \multicolumn{2}{|c|}{$1.20(1.0-3.25)$} \\
\hline Significance & \multicolumn{6}{|c|}{$\mathrm{p}_{1}<0.001^{*}, \mathrm{p}_{2}<0.001^{*}, \mathrm{p}_{3}=0.049^{*}$} \\
\hline \multicolumn{7}{|l|}{ CEA (ng/ml) } \\
\hline Median & \multicolumn{2}{|c|}{$8.11(6.3-11.7)$} & \multicolumn{2}{|c|}{$1.89(1.24-3.2)$} & \multicolumn{2}{|c|}{$2.60(1.4-4.1)$} \\
\hline Significance & \multicolumn{6}{|c|}{$\mathrm{p} 1<0.001^{*}, \mathrm{p} 2<0.001^{*}, \mathrm{p} 3=0.622$} \\
\hline \multicolumn{7}{|c|}{ CA19-9 (U/ml) } \\
\hline Median & 33.1 & 9.2) & 7.7 & & 7.72 & \\
\hline Significance & $\mathrm{p} 1<$ & $2<0$. & $=0.5$ & & & \\
\hline
\end{tabular}

p1: p value for comparing between group I and group II.

p2: $p$ value for comparing between group I and group III.

p3: $\mathrm{p}$ value for comparing between group II and group III.

*: Statistically significant at $p \leq 0.05$.

Group I: Colorectal adenocarcinoma.

Group II: Colorectal polyp diagnosed by colonoscopy.

Group III: Control. 
Table 2 Comparison between the studied groups according to $\mathrm{H} 19$ and Beta catenin

\begin{tabular}{|c|c|c|c|c|}
\hline & $\begin{array}{l}\text { Group I } \\
(n=40)\end{array}$ & $\begin{array}{l}\text { Group II } \\
(n=40)\end{array}$ & $\begin{array}{l}\text { Group III } \\
(n=20)\end{array}$ & $P$ \\
\hline \multicolumn{5}{|c|}{ H19 (fold increase) } \\
\hline Min. - Max. & $0.04-10.20$ & $0.05-9.34$ & $0.23-4.56$ & \multirow[t]{2}{*}{$0.010^{*}$} \\
\hline Median (IQR) & $1.24(0.54-2.17)$ & $0.70(0.38-1.73)$ & $0.49(0.29-1.01)$ & \\
\hline Significance & \multicolumn{4}{|c|}{$\mathrm{p} 1=0.019^{*}, \mathrm{p} 2=0.006^{*}, \mathrm{p} 3=0.411$} \\
\hline \multicolumn{5}{|c|}{$\beta$-catenin $(\mathrm{pg} / \mathrm{ml})$} \\
\hline Min.-Max. & $127.0-4,520.0$ & $99.0-3,395.0$ & $90.50-1,009.0$ & \multirow[t]{2}{*}{$0.001^{*}$} \\
\hline Median (IQR) & 305 (199.7-509.5) & $211.25(139-305)$ & $151.0(119.5-233.3)$ & \\
\hline Significance & \multicolumn{4}{|c|}{$\mathrm{p} 1=0.009^{*}, \mathrm{p} 2<0.001^{*}, \mathrm{p} 3=0.138$} \\
\hline
\end{tabular}

p1: p value for comparing between group I and group II.

p2: p value for comparing between group I and group III.

p3: $p$ value for comparing between group II and group III.

*: Statistically significant at $p \leq 0.05$.

Group I: Colorectal adenocarcinoma.

Group II: Colorectal polyp diagnosed by colonoscopy.

Group III: Control.

Table 3 Receiver-operating characteristics curve analysis of $\mathrm{H} 19$ serum expression $\left(2^{-\Delta \Delta C \mathrm{CT}}\right)$, $\beta$-catenin, carcinoembryonic antigen serum level, and serum CA19.9 activities for group I versus group II

\begin{tabular}{|l|l|l|l|l|l|l|l|l|}
\hline & AUC & $P$ & $95 \%$ C.I & Cut off & Sensitivity & Specificity & PPV & NPV \\
\hline CEA & $0.963^{*}$ & $<0.001^{*}$ & $0.914-1.011$ & $>4.56$ & 95.0 & 92.50 & 92.7 & 94.9 \\
\hline CA19-9 & $0.943^{*}$ & $<0.001^{*}$ & $0.896-0.991$ & $>19.45^{\#}$ & 95.0 & 87.50 & 88.4 & 94.6 \\
\hline H19 & $0.653^{*}$ & $0.019^{*}$ & $0.532-0.774$ & $>\mathbf{0 . 8 5}$ & 67.50 & 62.50 & 64.3 & 65.8 \\
\hline Catenin & $0.681^{*}$ & $0.005^{*}$ & $0.563-0.799$ & $>215.5$ & 67.50 & 57.50 & 61.4 & 63.9 \\
\hline H19+Catenin & $0.724^{*}$ & $0.001^{*}$ & $0.612-0.836$ & & 35.0 & 87.50 & 73.68 & 57.38 \\
\hline CEA+H19+Catenin & $0.965^{*}$ & $<0.001^{*}$ & $0.917-1.013$ & & 90.0 & 95.0 & 94.74 & 90.48 \\
\hline CA19-9+H19+Catenin & $0.948^{*}$ & $<0.001^{*}$ & $0.905-0.992$ & & 87.50 & 87.50 & 87.50 & 87.50 \\
\hline
\end{tabular}

Abbreviations: AUC, area under the curve; $\mathrm{Cl}$, confidence interval; NPV, negative predictive value; $p$-value, probability value; PPV, positive predictive value. $*$ : Statistically significant at $p \leq 0.05$

Group I: Colorectal adenocarcinoma.

Group II: Colorectal polyp.

\section{Discussion}

The lncRNA H19 was overexpressed in many types of cancer, like esophageal, gastric, hepatic, bladder, and breast cancer. $^{22}$ The present work has been conducted for assessing the serum H19 expression significance and to discuss the probability of using it as a serum biomarker for early CRC diagnosis in Egyptian patients.

Our study revealed that the H19 expression levels in cancer cases were significantly higher than those of colonic polyp patients.

In accordance with our results, Gharib E et al. ${ }^{23}$ found that among CRC cases, H19 expression in fecal colonocytes was higher than in colonic polyp patients. Also, Galamb et al. stated that the expression of H19 was elevated in the cancer tissue of CRC patients. ${ }^{24}$

Our study also showed that H19 expression level in cancer patients was significantly high when compared with con- trols, while polyp patients and controls did not show significant differences.

In agreement with our findings, the study by Ismail D et al. on Egyptian CRC patients stated that the expression level of H19 had shown an 11.38-fold increase in CRC cases in comparison with controls. However, H19 expression had not shown any significant difference among CRC cases who had and even those that did not have regional lymph node metastasis. ${ }^{19}$

Moreover, the study by Gharib et al. showed greater expression of H19 in fecal colonocytes in CRC cases than in controls. ${ }^{23}$ Also, many studies were performed on CRC tissue in comparison to surrounding normal tissues, and they found that the level of H19 expression in malignant tissue was higher than in normal tissue, as demonstrated by Yang et al., Yang et al., Ding et al. and Liang et al. ${ }^{13,22,25,26}$

Acting as a competitive endogenous RNA (ceRNA) for miR138 and miR-200a, lncRNA H19 enhances the tumor growth 


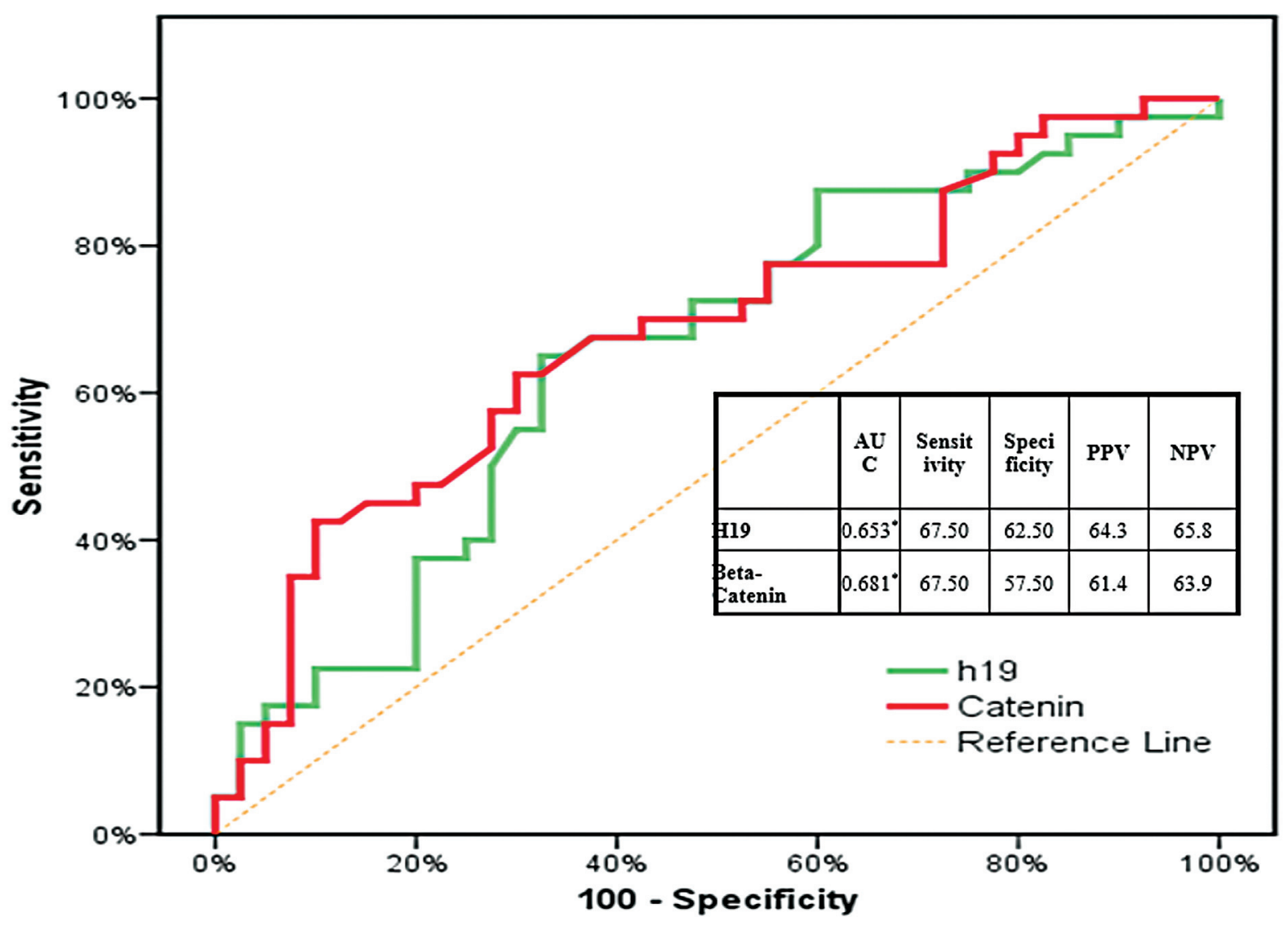

Fig. 2 Receiver-operating characteristic curve to differentiate group I from group II.

Table 4 Receiver operating characteristics curve for different parameters to differentiate group I from group III

\begin{tabular}{|l|l|l|l|l|l|l|l|l|}
\hline & AUC & $P$ & $95 \%$ C.I & Cut off & Sensitivity & Specificity & PPV & NPV \\
\hline CEA (ng/ml) & $0.976^{*}$ & $<0.001^{*}$ & $0.943-1.009$ & $>4.6$ & 95.0 & 90.0 & 95.0 & 90.0 \\
\hline CA19-9 (U/ml) & $0.938^{*}$ & $<0.001^{*}$ & $0.875-1.002$ & $>19.3$ & 95.0 & 80.0 & 90.5 & 88.9 \\
\hline H19 (fold increase) & $0.715^{*}$ & $0.007^{*}$ & $0.575-0.855$ & $>\mathbf{0 . 5 4}$ & 72.50 & 50.0 & 74.4 & 47.6 \\
\hline Catenin (pg/ml) & $0.763^{*}$ & $0.001^{*}$ & $0.634-0.891$ & $>\mathbf{1 9 8 . 5}$ & 75.0 & 65.0 & 81.1 & 56.5 \\
\hline
\end{tabular}

Abbreviations: AUC, area under a curve; $\mathrm{Cl}$, confidence interval; NPV, negative predictive value; $p$-value, probability value; PPV, positive predictive value.

*: Statistically significant at $p \leq 0.05$.

Group I: Colorectal adenocarcinoma.

Group III: Control.

by antagonizing their activities. It also causes the de-repression of their endogenous goals: vimentin, ZEB1, and ZEB2, which are markers for mesenchymal cells. Also, H19 sponged miRNA let-7 and modularized the expressions of let-7 targets, providing strong proof that $\mathrm{H} 19$ is a natural sponge for miRNAs causing endothelial-mesenchymal transition (EMT). ${ }^{26}$

Contrary to our study, Yoshimizu et al. suggested that H19 might also play a role in tumor suppression in mice by using in vivo murine models of carcinogenesis. They found that $H 19$ controlled the size of experimental carcinomas, the number of polyps in the Apc murine model of CRC, and delayed the appearance of metastasis. ${ }^{27}$ The discrepancy between such results and our results could be explained by the difference in the species and/or type of samples used since human and mouse have different genetics; the H19 locus may play a more complex role in humans than in mice. While our study was carried on samples from patients with sporadic polyp.

Wingless-related integration site (Wnt)/ $\beta$-catenin signaling pathway initiates the carcinogenesis. Many studies focused on the detection of higher levels of $\beta$-catenin in cancer tissues but not in the serum. Fortunately, some researchers have documented that $\beta$-catenin could be identified in human serum, and its level is associated with hepatocellular carcinoma (HCC) growth due to hepatitis C, hepatitis Blinked diseases, diabetes mellitus II, phosphatase and TENsin (PTEN) hamartoma tumor syndrome, and early-onset ulcerative colitis. Although there is a hyperactivated $\mathrm{Wnt} / \beta$ catenin signal and a great quantity of $\beta$-catenin aggregation 
in CRC, the diagnostic significance of serum $\beta$-catenin remains uncertain among $\mathrm{CRC}$ cases. $^{18}$

Our research demonstrated that serum $\beta$-catenin levels were significantly higher in cases with cancer compared with those with colonic polyp and controls. In the same line with our research, Li et al. stated that the level of serum $\beta$-catenin in cases with CRC is significantly elevated in relation to those in colonic polyp and in the control group. ${ }^{18}$ Also, our findings are supported by Kobayashi et al., who reported in their study that nuclear overexpression of $\beta$-catenin was observed in $35 \%$ of early-stage CRC patients and $42 \%$ of invasive cancer patients but was not observed in patients with polyps from either sporadic or FAP cases. Most CRC cases that were accompanied by polyps showed nuclear overexpression of $\beta$-catenin in the cancer area, but this was not observed in the polyps component. ${ }^{28}$

Also, Wong et al. mentioned that $\beta$-catenin was overexpressed in $8 \%$ of polyps and all CRC samples in comparison to normal tissues. Higher levels in CRC were significantly associated with lymph node metastasis. ${ }^{29}$ Also, Bourroul et al. found low expression of $\beta$-catenin in colonic polyps, whereas its expression was increased in colorectal carcinoma. ${ }^{30-32}$

Our study also showed that the levels of $\beta$-catenin among cases with colonic polyp and controls did not differ significantly. In contrast to our study, the level of $\beta$-catenin in the colonic polyp group was significantly higher than in healthy controls in a study conducted by Li et al. ${ }^{18}$

Finally, the ROC curve analysis was performed for analyzing the cut-off levels for $\mathrm{H} 19$ serum expression and serum $\beta$ catenin level above which patients are expected to have CRC, and we found that $\mathrm{H} 19$ and $\beta$-catenin did not show a better diagnostic performance over CEA or CA19-9. However, the combination of both markers with CEA or CA19-9 improved their specificity in the differentiation of CRC patients from those with polyp and controls. Thus, serum H19 and $\beta$ catenin can both help in the differentiation of CRC patients from colonic polyp patients and controls but cannot discriminate polyp patients from normal subjects.

The present study is important due to the high mortality rate of CRC, and the possibility of decreasing its mortality by reaching an early diagnosis. Also, the novelty of the study as, until now, very little is known about the significance of relative serum expression of $\mathrm{H} 19$ and $\beta$-catenin as biomarkers used in the early diagnosis of CRC. On the other hand, some limitations of the current study need to be addressed. First, the study subjects were restricted to the city of Alexandria. Second, the sample size of this study is relatively small, which may not have enough statistical power to explore the true association. Therefore, large populationbased prospective studies with an ethnically diverse population are warranted.

\section{Conclusion}

Serum expressions of $\mathrm{H} 19$ and $\beta$-catenin can significantly discriminate patients with CRC from those with polyp and from the normal population, which could help with screening for CRC.
Conflict of Interests

The authors declare no conflict of interests.

\section{References}

1 Yang H, Li X, Meng Q, et al. CircPTK2 (hsa_circ_0005273) as a novel therapeutic target for metastatic colorectal cancer. Mol Cancer 2020;19(01):13

2 Wiegering A, Ackermann S, Riegel J, et al. Improved survival of patients with colon cancer detected by screening colonoscopy. Int J Colorectal Dis 2016;31(05):1039-1045

3 Bailey CE, Hu C-Y, You YN, et al. Increasing disparities in the agerelated incidences of colon and rectal cancers in the United States, 1975-2010. JAMA Surg 2015;150(01):17-22

4 Pilonis ND, Bugajski M, Wieszczy P, et al. Long-term colorectal cancer incidence and mortality after a single negative screening colonoscopy. Ann Intern Med 2020;173(02):81-91

5 Seeff LC, Manninen DL, Dong FB, et al. Is there endoscopic capacity to provide colorectal cancer screening to the unscreened population in the United States? Gastroenterology 2004;127(06):1661-1669

6 Burch JA, Soares-Weiser K, St John DJ, et al. Diagnostic accuracy of faecal occult blood tests used in screening for colorectal cancer: a systematic review. J Med Screen 2007;14(03):132-137

7 Rho JH, Ladd JJ, Li CI, et al. Protein and glycomic plasma markers for early detection of adenoma and colon cancer. Gut 2018;67 (03):473-484

8 Smith RA, Andrews K, Brooks D, et al. Cancer screening in the United States, 2016: A review of current American Cancer Society guidelines and current issues in cancer screening. CA Cancer J Clin 2016;66(02):96-114

9 Duffy MJ, Lamerz R, Haglund C, et al. Tumor markers in colorectal cancer, gastric cancer and gastrointestinal stromal cancers: European group on tumor markers 2014 guidelines update. Int J Cancer 2014;134(11):2513-2522

10 Xie X, Tang B, Xiao Y-F, et al. Long non-coding RNAs in colorectal cancer. Oncotarget 2016;7(05):5226-5239

11 Hajjari M, Khoshnevisan A, Shin YK. Molecular function and regulation of long non-coding RNAs: paradigms with potential roles in cancer. Tumour Biol 2014;35(11):10645-10663

12 Schwarzenbach $\mathrm{H}$. Diagnostic relevance of circulating cell-free and exosomal microRNAs and long non-coding RNAs in blood of cancer patients. Journal of Laboratory Medicine. 2016;40(05): 345-353

13 Yang W, Ning N, Jin X. The IncRNA H19 promotes cell proliferation by competitively binding to miR-200a and derepressing $\beta$-catenin expression in colorectal cancer. BioMed Res Int 2017; 2017:2767484

14 Chen DD, Hui LL, Zhang XC, Chang Q. NEAT1 contributes to oxLDL-induced inflammation and oxidative stress in macrophages through inhibiting miR-128. J Cell Biochem 2018;120(02): 2493-2501

15 Ohtsuka M, Ling H, Ivan C, et al. H19 Noncoding RNA, an Independent Prognostic Factor, Regulates Essential Rb-E2F and CDK8- $\beta$-Catenin Signaling in Colorectal Cancer. EBioMedicine 2016;13:113-124

16 Schwarzenbach $\mathrm{H}$. Biological and clinical relevance of H19 in colorectal cancer patients. EBioMedicine 2016;13:9-10

17 Sánchez Y, Huarte M. Long non-coding RNAs: challenges for diagnosis and therapies. Nucleic Acid Ther 2013;23(01):15-20

18 Li S, Huang M, Liu Q et al. Serum Expression of $\beta$-Catenin Is a Potential Detection Marker in Patients with Colorectal Cancer. Dis Markers 2019;2019:5070524

19 Ismail DM, Shaker OG, Kandeil MA, Hussein RM. Gene expression of the circulating long noncoding RNA H19 and HOTAIR in Egyptian colorectal cancer patients. Genet Test Mol Biomarkers 2019;23(09):671-680

20 Kotz S, Balakrishnan N, Read CB, Vidakovic B. Encyclopedia of statistical sciences. $2^{\text {nd }}$ ed. Hoboken, N.J.: Wiley-Interscience; 2006 
21 Kirkpatrick LA, Feeney BC. A simple guide to IBM SPSS statistics for version 20.0. Student ed. Belmont, Calif.: Wadsworth, Cengage Learning; 2013

22 Yang W, Redpath RE, Zhang C, Ning N. Long non-coding RNA H19 promotes the migration and invasion of colon cancer cells via MAPK signaling pathway. Oncol Lett 2018;16(03):3365-3372

23 Gharib E, Nazemalhosseini-Mojarad E, Baghdar K, et al. Identification of a stool long non-coding RNAs panel as a potential biomarker for early detection of colorectal cancer. J Clin Lab Anal 2021;35(02):e23601

24 Galamb O, Barták BK, Kalmár A, et al. Diagnostic and prognostic potential of tissue and circulating long non-coding RNAs in colorectal tumors. World J Gastroenterol 2019;25(34): 5026-5048

25 Ding D, Li C, Zhao T, Li D, Yang L, Zhang B. LncRNA H19/miR-29b3p/PGRN axis promoted epithelial-mesenchymal transition of colorectal cancer cells by acting on Wnt signaling. Mol Cells 2018;41(05):423-435

26 Liang $\mathrm{W}-\mathrm{C}$, Fu W-M, Wong C-W, et al. The IncRNA H19 promotes epithelial to mesenchymal transition by functioning as miRNA sponges in colorectal cancer. Oncotarget 2015;6(26): 22513-22525

27 Yoshimizu T, Miroglio A, Ripoche M-A, et al. The H19 locus acts in vivo as a tumor suppressor. Proc Natl Acad Sci U S A 2008;105(34): 12417-12422

28 Kobayashi M, Honma T, Matsuda Y, et al. Nuclear translocation of beta-catenin in colorectal cancer. Br J Cancer 2000;82(10): 1689-1693

29 Wong SC, Lo ES, Lee KC, Chan JK, Hsiao WL. Prognostic and diagnostic significance of beta-catenin nuclear immunostaining in colorectal cancer. Clin Cancer Res 2004;10(04):1401-1408

30 Bourroul GM, Fragoso HJ, Gomes JWF, et al. The destruction complex of beta-catenin in colorectal carcinoma and colonic adenoma. Einstein (Sao Paulo) 2016;14(02):135-142

31 Kwon C, Cheng P, King IN, et al. Notch post-translationally regulates $\beta$-catenin protein in stem and progenitor cells. Nat Cell Biol 2011;13(10):1244-1251

32 van Es JH, van Gijn ME, Riccio O, et al. Notch/gamma-secretase inhibition turns proliferative cells in intestinal crypts and adenomas into goblet cells. Nature 2005;435(7044):959-963 